poorer cognition at 7 years. This indicates that early aEEGs may be useful in predicting functional outcome of preterm children at school age.

\section{NEURODEVELOPMENTAL OUTCOME AMONG MULTIPLES AND SINGLETONS: A REGIONAL NEONATAL INTENSIVE CARE UNIT'S EXPERIENCE IN TURKEY}

doi:10.1136/archdischild-2012-302724.1231

$1 Z$ Eras, ${ }^{2 B M}$ Özyurt, ${ }^{3} 0$ Erdeve, 'ED Sakrucu, ${ }^{2} S S$ Oguz, ${ }^{2} F E$ Canpolat, ${ }^{2} \mathrm{~N}$ Uras, ${ }^{4} \mathrm{U}$ Dilmen. ${ }^{1}$ Developmental Behavioral Pediatrics Unit; ${ }^{2}$ Neonatology, Zekai Tahir Burak Maternity and Teaching Hospital; ${ }^{3}$ Neonatology, Ankara University, Faculty of Medicine; ${ }^{4}$ Neonatology, Zekai Tahir Burak Maternity and Teaching Hospital, Yıldırım Beyazıt University Department of Pediatrics, Ankara, Turkey

Objective The aim of this study was to compare the neurodevelopmental outcome at 12-18 months' corrected age between multiples and singleton preterm infants.

Methods We designed a prospective study of preterm infants $(\leq 32$ weeks gestation) born and hospitalized in the neonatal intensive care unit between November 2008 and November 2009, whose assessments were performed at 12-18 months' corrected age. Neurodevelopmental impairment was defined as the presence of any one of the following: moderate or severe cerebral palsy, severe bilateral hearing loss or bilateral blindness, mental developmental index score or psychomotor developmental index score less than 70 . Results were compared for both multiples and singleton infants.

Results A hundred and fifty-nine multiples and 211 singleton infants were assessed at 12-18 months' corrected age. The neurodevelopmental outcome including all parameters at 12-18 months' corrected age in multiples was not significantly different from singleton preterm infants.

Conclusions Multiple gestation in preterm infants is not associated with an increased risk of neurodevelopmental impairment at 12-18 months' corrected age compared to singleton preterm infants. For further information long-term and high-participated neurodevelopmental follow-up and evaluation at pre-school age will be needed.

\section{DO ORAL PROBIOTICS AFFECT GROWTH AND NEURODEVELOPMENTAL OUTCOMES IN VERY LOW BIRTH WEIGHT PRETERM INFANTS?}

doi:10.1136/archdischild-2012-302724.1232

${ }^{1} \mathrm{FN}$ Sarı, ${ }^{2} \mathrm{Z}$ Eras, ${ }^{3} \mathrm{EA}$ Dizdar, ${ }^{4} 0$ Erdeve, ${ }^{3} \mathrm{SS}$ Oguz, ${ }^{3} \mathrm{~N}$ Uras, ${ }^{5} \mathrm{U}$ Dilmen. ${ }^{1}$ Noenatology; ${ }^{2}$ Developmental Behavioral Pediatrics Unit; ${ }^{3}$ Neonatology, Zekai Tahir Burak Maternity and Teaching Hospital; "Neonatology, Ankara University, Faculty of Medicine${ }^{5}$ Neonatology, Zekai Tahir Burak Maternity and Teaching Hospital/YIIdırım Beyazıt University Department of Pediatrics, Ankara, Turkey

Objective To evaluate the growth and neurodevelopmental outcomes of very low birth weight (VLBW) preterm infants supplemented with oral probiotics for the prevention of necrotising enterocolitis (NEC).

Study Design This prospective follow-up study was conducted in a cohort of VLBW preterm infants enrolled in a randomizedcontrolled clinical trial to evaluate the efficacy of oral probiotics for the prevention of NEC. Growth outcomes included weight, length and head circumference. Neurodevelopmental assessment was done using the Bayley Scales of Infant Development II (BSID-II). The primary outcome was neurodevelopmental impairment at 18-24 months' corrected age.

Results A total of 221 infants completed the trial protocol. Of the 208 infants eligible for follow-up, 174 infants (86 in the probiotics group and 88 in the control group) were evaluated. There were no significant difference in growth and neurodevelopmental outcomes between the two groups.
Conclusion Oral probiotic administrated to VLBW infants to reduce the incidence and severity of NEC started with the first feed did not affect growth and neurodevelopmental outcomes at 18-24 months' corrected age.

\section{THE IMPACT OF MEDICAL HOME MODEL ON NEURODEVELOPMENTAL OUTCOMES OF VERY PRETERM INFANTS}

doi:10.1136/archdischild-2012-302724.1233

'Z Eras, ${ }^{2} \mathrm{G}$ Kanmaz, ${ }^{2} \mathrm{BM}$ Ozyurt, ${ }^{2} \mathrm{FE}$ Canpolat, ${ }^{1} \mathrm{ED}$ Sakrucu, ${ }^{3} \mathrm{U}$ Dilmen. ${ }^{1}$ Developmental Behavioral Pediatrics Unit; ${ }^{2}$ Neonatology, Zekai Tahir Burak Maternity and Teaching Hospital; ${ }^{3}$ Neonatology, Zekai Tahir Burak Maternity and Teaching Hospital, Yıldırım Beyazit University Department of Pediatrics, Ankara, Turkey

Objective The aim of the study is to compare the 2-year neurodevelopmental outcome of very low birth weight and/or very preterm infants followed with "medical home model" implemented in a big maternity hospital in Turkey with the primary health care.

Methods We designed a prospective controlled study of infants born $\leq 32$ week's gestation and/or $\leq 1500 \mathrm{~g}$ and hospitalized. After discharge, intervention group were followed with in the concept of medical home model and control group were followed in the concept of primary standart health care. At 18-24 months' of corrected age, the neurological examinations and the developmental assessments using the Bayley Scales of Infant Development-II were performed.

Results The cerebral palsy rates in the intervention and control group were $10.6 \%(n=17)$ and $17.4 \%(n=27)$ respectively and the difference was not statistically significant $(p=0.107)$. Whereas the rate of neurodevelopmental impairment in the intervention group was significantly lower than the control group $(25 \%$ and $38,7 \%$; $\mathrm{p}=0.011$ ).

Conclusion We demonstrated that beginning a good follow-up process within the context of medical home model, efficient developmental support and performing guidance for early diagnose reduced the negative effects of VLBW and/or prematurity on neurodevelopmental impairment at 2 years of age.

\section{4 PREDICTORS OF LITERACY IN VERY PRETERM INFANTS: A LONGITUDINAL STUDY}

doi:10.1136/archdischild-2012-302724.1234

'A Guarini, 'A Sansavini, 'S Savini, ${ }^{2} \mathrm{R}$ Alessandroni, ${ }^{2} \mathrm{G}$ Faldella. 'Department of Psychology; ${ }^{2}$ Institute of Neonatology, University of Bologna, Bologna, Italy

Background and Aims As revealed by several studies, a very preterm birth may affect language, executive functions, verbal short term memory and literacy. The aim of this study was to investigate these competencies in very preterms compared to full terms, thus describing how language, executive functions and verbal short-term memory observed at the end of preschool age affect literacy at school age.

Methods Forty-two monolingual Italian very preterms (mean gestational age 29.7 weeks), with no history of major cerebral damage, were followed longitudinally at 6 years by investigating language (vocabulary, grammar, and phonological awareness), executive functions (syllabic and phonemic fluency) and verbal short-term memory (vowel span, non-word repetition) and again at 8 years on literacy (word and non-word reading and spelling). Two crosssectional groups of full term children were recruited as control groups ( 34 and 26 children at 6 and 8 years respectively).

Results Preterms showed lower abilities in language at 6 years and in literacy at 8 years, while no differences between groups regarding syllabic and phonemic fluency and short-term memory were found. Linear regression analyses revealed that in the preterm sample both language and verbal short-term memory had a predictive role on 
literacy with some differences in function of word versus non-word reading and writing.

Conclusions These findings revealed the importance to analyse both language and short-term memory in preterms at the end of preschool age, with relevant implications for interventions to improve literacy at school age.

\section{DEVELOPMENT AND VALIDATION OF A SCALE TO ASSESS KNOWLEDGE OF OUTCOMES FOLLOWING PRETERM BIRTH}

doi:10.1136/archdischild-2012-302724.1235

'D Henderson, ${ }^{1} \mathrm{C}$ Beer, ${ }^{2} \mathrm{D}$ Wolke, ${ }^{3} \mathrm{~S}$ Johnson. ${ }^{1}$ School of Community Heath Sciences, University of Nottingham, Nottingham; ${ }^{2}$ Warwick Medical School, University of Warwick, Coventry; ${ }^{3}$ Department of Health Sciences, University of Leicester, Leicester, UK

Background and Aims Preterm children are at high-risk for special educational needs. Education professionals' (EPs) knowledge of health conditions is crucial for providing appropriate support, however no studies have investigated their knowledge in this area. To facilitate such research we developed a scale to assess knowledge of outcomes following preterm birth.

Methods Following a comprehensive literature review, 35 forced choice (true/false/don't know) items were developed to assess knowledge of neurodevelopmental and educational outcomes. Item scores were summed to provide a total knowledge score (range $0-35)$. The scale was completed by 120 EPs and 70 experts in the field (neonatologists/paediatricians).

Results EPs' responses revealed floor effects for 2 items which were removed. The remaining 33-item scale had excellent internal reliability (Cronbach's Alpha=0.82). EPs' knowledge scores were normally distributed (Mean 11.3; SD 5.4) and differed significantly by level of training $(\mathrm{F}(3,111)=2.78, \mathrm{p}=0.045)$ indicating construct validity. Experts' knowledge scores were not normally distributed (Median 26.5; IOR 23.0-29.0) and were significantly higher than EPs $(p<0.001)$ indicating discriminative validity. Principal components factor analysis revealed two factors:

1. developmental problems, internalising difficulties and attainment,

2. need for additional support in the classroom.

EPs' scores were significantly lower than experts on both subscales.

Conclusions This short scale has good psychometric properties and provides a useful tool for teaching and assessing clinical and education professionals' knowledge of preterm birth. Study results revealed the need to improve EPs' knowledge of sequelae of prematurity if they are to support increasing numbers of preterm children in the classroom.

\section{SUPPORTING THE SCHOOLING OF VERY PRETERM CHILDREN: EDUCATION PROFESSIONALS' OPINIONS AND INFORMATION NEEDS}

doi:10.1136/archdischild-2012-302724.1236

${ }^{1} \mathrm{D}$ Henderson, ${ }^{1} \mathrm{C}$ Beer, ${ }^{2} \mathrm{D}$ Wolke, ${ }^{3} \mathrm{~S}$ Johnson. ${ }^{1}$ School of Community Heath Sciences, University of Nottingham, Nottingham: ${ }^{2}$ Warwick Medical School, University of Warwick, Coventry; ${ }^{3}$ Department of Health Sciences, University of Leicester, Leicester, UK

Background and Aims Increasing numbers of very preterm (VP; < 32 weeks) children with special educational needs are entering, and challenging, the education system. At present we know little about teachers' information needs or opinions regarding how to support these children.

Methods Preschool and primary education professionals completed a questionnaire to elicit opinions regarding their information needs, disclosure of birth status and delayed school entry for VP children. Respondents rated how strongly they agreed with 10 statements using a 5-point Likert scale; responses ranged from strongly agree to strongly disagree. Additional questions explored training received and demographic information.

Results Of the 120 respondents, $89 \%$ felt they were likely to teach a VP child and that educational management was the role of the class teacher. However, only $6 \%$ reported having received sufficient training about VP children and $>90 \%$ agreed they would like more information about strategies to support VP children's learning. $92 \%$ of respondents agreed that disclosing a child's preterm birth status would be beneficial and none felt it would lead to problems associated with labelling. A small majority of teachers were supportive of parents delaying $(56 \%)$ or deferring $(58 \%)$ their child's school entry. Conclusions This survey revealed that a worrying number of early years' education professionals received no formal training regarding the educational needs of VP children and most felt inadequately equipped to support these children in their classroom. There is a pressing need for clinicians to communicate evidence-based findings to facilitate ongoing management of VP children at school.

\section{DEVELOPMENT AND QUALITY OF LIFE IN NICU GRADUATES AND HEALTHY NEWBORNS WITH PCHI AT 3-5 YEARS OF AGE AFTER NHS}

doi:10.1136/archdischild-2012-302724.1237

${ }^{1}$ EA van de Ven, ${ }^{1} H L M$ van Straaten, ${ }^{2}$ AM Oudesluys-Murphy, ${ }^{2} \mathrm{AMH}$ Korver. ${ }^{1}$ Dept of Neonatology, Isala Clinics, Zwolle; '2Dept of Pediatrics, Leiden University Medical Center, Leiden, The Netherlands

Background NICU graduates have both an increased risk of permanent childhood hearing impairment (PCHI) and delayed psychomotor development. Little follow up is available after introduction of neonatal hearing screening (NHS).

Aim Comparison of language and psychomotor development as well as quality of life in NICU graduates vs. well baby clinic (WBC) newborns with PCHI at the age of 3-5 years.

Method All children (born 2003-2005) with PCHI identified in the Netherlands at speech and hearing centres were included. Development and quality of life (OOL) were measured at age $3-5$ yrs by using the MacArthur Communicative Development Inventory, Child Development Inventory (CDI), and Pediatric QOL Inventory 4.0.

Results Twenty-six NICU graduates and 64 WBC newborns completed all measurements. Language development showed significant difference for total words signed (23.3 vs 10.6 ; $\mathrm{p}=0,009)$. All other scores in NICU graduates on subscales of MacArthur tend to be lower. Though CDI scores were not statistically significantly different, the scores of social (70.1 vs 75.2), self-help (80.0 vs 86.2 ) and gross motor development (72.0 vs 83.4 ) were considered clinically significant. Total QOL score differed not significantly (79.4 vs 85.5$)$, inclusive physical functioning ( 85.7 vs 90.4 ) but the subscales social functioning (75.4 vs 85.3; $\mathrm{p}=0,004)$ and psychosocial health summary score (75.9 vs $82.4 ; \mathrm{p}=0,018)$ did for NICU graduates.

Conclusion After NHS NICU graduates with PCHI pursuit to have an increased risk for delayed language and psychomotor development compared to their 'healthy' peers with PCHI. Also quality of life is negatively affected.

\section{INCIDENCE OF CEREBRAL PALSY IN PRETERM BORN CHILDREN DID NOT CHANGE SINCE 2004}

doi:10.1136/archdischild-2012-302724.1238

FV van Daalen, EF Stremmelaar, AF Bos. Department of Pediatrics, Division of Neonatology, University Medical Center, University of Groningen, Groningen, The Netherlands

Introduction During the last decade survival rates of preterm children continuously improve. It is under debate whether this influences the incidence of cerebral palsy (CP). 